This item was submitted to Loughborough's Research Repository by the author.

Items in Figshare are protected by copyright, with all rights reserved, unless otherwise indicated.

\title{
Voluntary water intake during and following moderate exercise in the cold
}

PLEASE CITE THE PUBLISHED VERSION

http://dx.doi.org/10.1123/ijsnem.2013-0034

\section{PUBLISHER}

(c) Human Kinetics Publishing as accepted for publication

\section{VERSION}

AM (Accepted Manuscript)

\section{PUBLISHER STATEMENT}

This work is made available according to the conditions of the Creative Commons Attribution-NonCommercialNoDerivatives 4.0 International (CC BY-NC-ND 4.0) licence. Full details of this licence are available at: https://creativecommons.org/licenses/by-nc-nd/4.0/

\section{LICENCE}

CC BY-NC-ND 4.0

\section{REPOSITORY RECORD}

Mears, Stephen A., and Susan M. Shirreffs. 2019. "Voluntary Water Intake During and Following Moderate Exercise in the Cold". figshare. https://hdl.handle.net/2134/20399. 
1 Voluntary water intake during and following moderate exercise in the cold 2

3 Stephen A Mears, Susan M Shirreffs

4 School of Sport, Exercise and Health Sciences, Loughborough University, Loughborough, 5 LE11 3TU, UK

6

7 Corresponding Author:

8 Stephen A Mears

9 School of Sport, Exercise and Health Sciences, Loughborough University, Loughborough, 10 LE11 3TU, UK

11 Telephone: 01509226352

12 Fax: 01509226301

13 Email: S.A.Mears@lboro.ac.uk

14

15 Running head: Voluntary water intake in the cold 16 
17 Abstract

18 Exercising in cold environments results in water losses, yet examination of resultant

Key Words: water intake, cold, thirst, osmolality a blunted thirst response. voluntary water intake has focussed on warm conditions. The purpose of the study was to assess voluntary water intake during and following exercise in a cold compared to a warm environment. Ten healthy males (22 \pm 2 years, $67.8 \pm 7.0 \mathrm{~kg}, 1.77 \pm 0.06 \mathrm{~m}, \dot{\mathrm{VO}_{2 p e a k}} 60.5 \pm 8.9$ $\mathrm{ml} \cdot \mathrm{kg}^{-1} \cdot \mathrm{min}^{-1}$ ) completed two trials (7-8d). In each trial subjects sat for 30 minutes before cycling at $70 \% \dot{\mathrm{VO}_{2 p e a k}}(162 \pm 27 \mathrm{~W})$ for 60 minutes in $25.0 \pm 0.1^{\circ} \mathrm{C}, 50.8 \pm 1.5 \%$ relative humidity (RH) (warm) or $0.4 \pm 1.0^{\circ} \mathrm{C}, 68.8 \pm 7.5 \% \mathrm{RH}$ (cold). Subjects then sat for 120 minutes at $22.2 \pm 1.2^{\circ} \mathrm{C}, 50.5 \pm 8.0 \% \mathrm{RH}$. Ad libitum drinking was allowed during the exercise and recovery periods. Urine volume, body mass, serum osmolality and sensations of thirst were measured at baseline, post-exercise and after 60 and 120 minutes of the recovery period. Sweat loss was greater in the warm trial $(0.96 \pm 0.18 \mathrm{l} \mathrm{v} 0.48 \pm 0.15 \mathrm{l})(\mathrm{p}<0.0001)$ but body mass losses over the trials were similar $(1.15 \pm 0.34 \%$ (cold) v $1.03 \pm 0.26 \%$ (warm)). More water was consumed throughout the duration of the warm trial $(0.81 \pm 0.42 \mathrm{l} \mathrm{v} 0.50 \pm 0.49 \mathrm{l}$; $\mathrm{p}=0.001)$. Cumulative urine output was greater in the cold trial $(0.81 \pm 0.46 \mathrm{v} 0.54 \pm 0.31 \mathrm{l})$ $(\mathrm{p}=0.036)$. Post-exercise serum osmolality was higher compared to baseline in the cold $\left(292 \pm 2\right.$ v $287 \pm 3$ mOsm. $\left.\mathrm{kg}^{-1}, \mathrm{p}<0.0001\right)$ and warm trials $\left(288 \pm 5 \mathrm{v} 285 \pm 4 \mathrm{mOsm} . \mathrm{kg}^{-1}\right.$; $\mathrm{p}=0.048)$. Thirst sensations were similar between trials $(\mathrm{p}>0.05)$. Ad libitum water intake adjusted so that similar body mass losses occurred in both trials. In the cold there appeared to 
Introduction

It is well documented in the literature that dehydration during and resulting from endurance exercise can impair performance, particularly when exercise is conducted in temperate or hot conditions (Cheuvront, Carter, \& Sawka, 2003; Murray 1995; Wendt, van Loon, \& Lichtenbelt, 2007). Dehydration resulting in body mass losses of greater than $2 \%$ body mass loss have been shown to have a negative impact on performance both physically (Sawka et al., 2007) and cognitively (Grandjean \& Grandjean, 2007). One of the main mechanisms of dehydration is sweat loss which is increased by exercise in the heat (Galloway \& Maughan, 1997). Although often to a lesser extent than in warm and humid conditions, dehydration is still apparent in the cold. This is in part due to many athletes wearing several layers of clothing thus creating a warm microenvironment for them to exercise in. In the cold, water losses can occur through sweating, cold induced diuresis and respiratory losses and in addition to this there is a reduction in voluntary water intake (Freund \& Sawka, 1995). Cold environments, in relation to exercise studies, are often described as less than $10^{\circ} \mathrm{C}$ with many studies using temperatures of $0-7^{\circ} \mathrm{C}$ (Cheuvront, Carter, Castellani, \& Sawka, 2005; Kenefick, Hazzard, Mahood, \& Castellani, 2004ab; Kenefick, St Pierre, Riel, Cheuvront, \& Castellani, 2008; O’Brien, Young, \& Sawka, 1998).

Despite the sweat losses in cold environments, water intake is often reduced and is often insufficient to replace the water losses that have occurred (Maughan, Shirreffs, Merson, \& Horswill, 2005). It has been shown that sweat losses during 90 minute football training sessions were similar in a cold (Maughan et al., 2005) and hot (Shirreffs et al., 2005) environment, however this could have been attributed to greater amounts of clothing worn in the cold therefore creating a warm microclimate.

With many researchers concentrating on exercise performance and water intake in the heat, literature examining thirst and voluntary dehydration in the cold is sparse. Research has focussed on low to moderate intensity exercise (50\% $\left.\dot{\mathrm{VO}}_{2 \max }\right)$ (Kenefick et al., 2004ab), temperatures that have not been very cold $\left(\sim 7-10^{\circ} \mathrm{C}\right)$ (O’Brien et al. 1998) and work in field environments where hormonal responses have not been analysed and clothing induced warm microclimates are often created (Maughan et al., 2005; Seifert, Burke, White, \& Luetkemeier, 2006). Examining voluntary dehydration with inclusion of these factors will assist with 
74 assessment of the prevalence or potential for performance influencing dehydration levels 75 occurring and whether further investigation is warranted into a potential effect on 76 performance following exercise in the cold. Through measurement of the associated 77 physiological mechanisms, an improved understanding of thirst and voluntary dehydration 78 can be determined and therefore greater knowledge of water intake requirements when 79 exercising in the cold. The aim of this study was to assess voluntary water intake and the 80 response to thirst following moderate intensity exercise in the cold through measurement of 81 blood indices and observed behaviour. It was hypothesised that voluntary water intake would 82 be less during and following exercise in a cold environment primarily due to reduced sweat 83 losses. 
Methods

\section{Subjects}

Ten healthy male subjects (age $22 \pm 2$ years, mass $67.8 \pm 7.0 \mathrm{~kg}$, height $1.77 \pm 0.06 \mathrm{~m}, \dot{\mathrm{V}}$ $\mathrm{O}_{\text {2peak }} 60.5 \pm 8.9 \mathrm{ml} . \mathrm{kg}^{-1} \cdot \mathrm{min}^{-1}$ ) were recruited. They took part in two trials, undertaken in a counter-balanced design. All subjects had the experimental protocol explained to them in writing and verbally. Subjects were not acclimatised to the heat or cold (i.e. had not visited hot or cold climates in the month preceding the first trial and throughout the duration of the trial). Subjects provided written informed consent and the experiment was approved by the Loughborough University Ethical Advisory Committee.

\section{Experimental protocol}

Subjects visited the laboratory four times for a $\dot{\mathrm{V}} \mathrm{O}_{2 \text { peak }}$ test, a familiarisation trial and two experimental trials; warm and cold (schematic of the trial is presented in Figure 1). A discontinuous incremental test to volitional fatigue on an electrically braked cycle ergometer (Lode Corival; Lode BV, Groningen, Netherlands) was performed on the first visit to measure $\dot{\mathrm{VO}}_{2 \text { peak. }}$ Expired gas was collected in Douglas bags during the final minute of each four minute incremental stage and analysed for oxygen and carbon dioxide concentration (Servomex 1400 Oxygen and Carbon Dioxide Gas Analyser; Servomex, Crowborough, UK). Gas volumes and temperature were measured using a Harvard dry gas meter (Harvard Apparatus Ltd., Edenbridge, UK) and thermometer (Edale Digital Thermometer D515: Edale instruments Ltd., Cambridge, UK) and corrected to STPD (standard temperature and pressure, dry).

In the three following visits, subjects attended for a familiarisation trial and two main experimental trials. The familiarisation trial was identical to the warm trial. Pre-trial standardisation occurred before each main trial and involved consuming $500 \mathrm{ml}$ of water two hours before arrival at the laboratory, to try and ensure subjects were in a euhydrated state, and to arrive following an overnight fast. Subjects were asked to record their dietary intake (food and drink consumed, amount and method of preparation), refrain from strenuous physical activity and consumption of alcohol in the 24 hours prior to arriving at the laboratory for the first experimental trial. Subjects were asked to repeat this prior the second experimental trial. Dietary intake was not analysed, but recorded to allow for replication. 
119 Separated by a period of seven or eight days, the experimental trials began in the morning at 120 the same time. Trials were identical apart from the environmental conditions exercise was 121 performed in. When arriving at the laboratory for the first trial, subjects did not know which 122 trial they were participating in. Using incomplete Latin square design, experimental trial 123 order was randomised. Exercise in the warm trial was performed at $\sim 25^{\circ} \mathrm{C}$, whilst the cold 124 trial was performed at $\sim 0^{\circ} \mathrm{C}$. In each trial, on arrival, subjects voided and the whole urine 125 volume measured and a $5 \mathrm{ml}$ sample retained for later analysis and had nude body mass 126 measured. A rectal thermistor $10 \mathrm{~cm}$ past the anal sphincter, skin thermistors were attached 127 at the chest, tricep, thigh and calf and a heart rate (HR) monitor was positioned (Polar 128 Vantage; Kempele, Finland). Core $\left(\mathrm{T}_{\mathrm{c}}\right)$ and skin temperature $\left(\mathrm{T}_{\mathrm{sk}}\right)$ were measured 129 continuously throughout the trials (BIOPAC MP100 System; BIOPAC, Santa Barbara, CA, 130 USA). Using the formula outlined by Ramanathan (1964) mean skin temperature was 131 calculated. To allow for postural alterations in blood flow, subjects sat for 30 minutes at 21.4 $132 \pm 1.0^{\circ} \mathrm{C}$ and $52.4 \pm 7.6 \%$ relative humidity $(\mathrm{RH})$. Baseline heart rate values every 10 minutes 133 were recorded. At the completion of the 30 minutes seated rest a $100 \mathrm{~mm}$ visual analogue 134 subjective feelings questionnaire comprising of thirst and dry mouth scales was administered $135(0 \mathrm{~mm}=$ not all thirsty/mouth not at all dry, $100 \mathrm{~mm}=$ very thirsty/mouth very dry). A 136 baseline (B) blood sample $(5.5 \mathrm{ml})$ was collected without stasis from an antecubital vein in 137 the arm.

139 Subjects cycled at $70 \% \dot{\mathrm{VO}}_{2 \max }(162 \pm 27 \mathrm{~W})$ for 60 minutes in either $25.0 \pm 0.1^{\circ} \mathrm{C}$ and $50.8 \pm$ $1401.5 \% \mathrm{RH}$ (warm) or $0.4 \pm 1.0^{\circ} \mathrm{C}$ and $68.8 \pm 7.5 \% \mathrm{RH}$ (cold). Every 10 minutes heart rate was 141 recorded and subjects were asked to provide a rating of their perceived exertion (RPE) and 142 thermal sensation. Subjects had free access to tap water maintained at a temperature of $11 \pm$ $1433^{\circ} \mathrm{C}$ throughout the duration of the exercise. The amount of water consumed was measured 144 but the subject was not made aware of the volume or that the volume was being measured. 145 Subjects were informed at the start that they could drink as they wanted and that the bottle 146 would be refilled if necessary and were provided with no external cues to drink. During the 147 familiarisation trial expired gas was collected between 14-15 minutes and 29-30 minutes to 148 confirm the correct workload was being performed. Immediately following completion of 149 exercise (post-exercise, PE), a blood sample (5.5 ml) was collected without stasis from an antecubital vein and thirst and dry mouth subjective feelings questionnaires were completed. 
151 Subjects voided, the volume was measured and a $5 \mathrm{ml}$ sample was retained for later analysis

152

153

154

155

156

157

158

159

160

161

162

163

164

165

166

167

168

169

170

171

172

173

174

175

176

177

178

179

180

181

182

183 and had body mass measured. Body mass was measured in clothing (trainers, socks and shorts) and with thermistors still attached. The mass of the thermistors and clothing were subtracted from the body mass recorded. Subjects rested for 120 minutes in $22.2 \pm 1.2^{\circ} \mathrm{C}$ and $50.5 \pm 8.0 \% \mathrm{RH}$ with ad libitum water $\left(11 \pm 3^{\circ} \mathrm{C}\right)$ intake measured during each 30 minute period. As during the exercise period, subjects were unaware of this. Heart rate and thermal sensation were measured every 10 minutes. At 60 and 120 minutes a blood sample (5.5 ml) was collected without stasis from an antecubital vein in the arm and thirst and dry mouth subjective feelings questionnaires were completed. Following this, subjects voided, the urine volume was measured and a $5 \mathrm{ml}$ sample was retained for later analysis and they then had body mass measured. After completion of the body mass measurement, subjects were allowed to leave the laboratory. At 10 minute intervals throughout the trials, temperature and relative humidity were measured (RH85 Digital Thermo-Hygrometer; Omega, Manchester, UK). To prevent the development and influence microclimates, during each trial subjects wore only shorts, socks and trainers.

\section{Sample analysis}

For each $5.5 \mathrm{ml}$ venous blood sample, $2.5 \mathrm{ml}$ was aliquoted and mixed with anticoagulant $\left(\mathrm{K}^{+}\right.$ EDTA; 1.5 mg.ml ${ }^{-1}$ ). From this, plasma was separated and part was refrigerated for subsequent osmolality analysis by freezing point depression (Gonotec Osmomat auto Cryoscopic Osmometer; Gonotec, Berlin, Germany), and the remainder was frozen at $-80^{\circ} \mathrm{C}$ for later analysis of hormone concentration. A further $1.0 \mathrm{ml}$ was aliquoted and mixed with anticoagulant ( $\mathrm{K}^{+}$EDTA; $\left.1.5 \mathrm{mg} \cdot \mathrm{ml}^{-1}\right)$ for analysis of haemoglobin concentration, haematocrit and glucose concentration. Serum was removed from the remaining blood $(\sim 2.0$ $\mathrm{ml}$ ) which was allowed to clot and was centrifuged at 3000rpm and $4^{\circ} \mathrm{C}$ for 15 minutes. Serum was later analysed for potassium and sodium concentration by flame photometry (Corning Clinical Flame Photometer 410C; Corning Ltd., Halstead, Essex, UK) and osmolality analysis by freezing point depression (Gonotec Osmomat auto Cryoscopic Osmometer; Gonotec, Berlin, Germany). Haemoglobin concentration was measured in duplicate using the cyanmethaemoglobin method. Haematocrit was measured in triplicate and determined by micro-centrifugation. Using haemoglobin concentrations and haematocrit values blood, plasma and red blood cell volume changes were calculated (method of Dill \& Costill, 1974). A $100 \mu \mathrm{l}$ sample of anticoagulated blood was pipetted into 0.3M perchloric 
184 acid in a ratio of 1:10 in duplicate for analysis of glucose by the GOD-PAP method (Randox

185 Laboratories Ltd., Crumbin, UK).

186

187 Following measurement of total sample volume and retention of a $5 \mathrm{ml}$ sample, urine was

188 analysed for osmolality through freezing point depression (Gonotec Osmomat auto

189 Cryoscopic Osmometer; Gonotec, Berlin, Germany) and for potassium and sodium

190 concentration by flame photometry (Corning Clinical Flame Photometer 410C; Corning Ltd.,

191 Halstead, Essex, UK). All urine analysis was carried out in duplicate.

192

193 Statistical analysis

194 Data were checked for normality of distribution using Shapiro-Wilks tests. All samples were 195 normally distributed and subsequently either paired samples t-tests or repeated measures

196 ANOVA was performed. If a significant main or interaction effect was found, a paired 197 samples t-tests with Bonferroni correction were performed to identify where the statistical 198 differences occurred and also used on significant and non-significant interaction effects. 199 Pearson's product moment correlation coefficients were calculated between physiological 200 and behavioural variables closely related to water balance. Statistical significance was 201 accepted when $\mathrm{p}<0.05$. Data expressed as mean \pm SD. 
203

Results

204

205

206

207

208

209

210

211

212

213

214

215

216

217

218

219

220

221

222

223

224

225

226

227

228

229

230

231

232

233

234

235

Baseline measures

Baseline measures of body mass (67.96 \pm 6.33 v $67.69 \pm 6.42 \mathrm{~kg})$, serum osmolality (287 \pm 3 v $285 \pm 4$ mOsmol.kg $\left.{ }^{-1}\right)$, urine osmolality $(320 \pm 205$ v $432 \pm 228$ mOsmol.kg-1) and sensations of thirst (39 \pm 23 v $42 \pm 18$ ) and mouth dryness (36 \pm 23 v $38 \pm 23$ ) were similar between cold and warm trials respectively ( $>>0.05)$. The results indicate that subjects arrived in a similar state of euhydration (Sawka et al., 2007).

\section{Body mass}

Body mass losses over the trials were similar ( $>0.05)$ (Table 1) but body mass had decreased from baseline values in both trials $(\mathrm{p}<0.05)$. After exercise, one subject in the cold trial and two in the warm trial had consumed more water than they had lost and thus, had gained weight.

\section{Water balance and subjective feeling questionnaires}

Sweat losses during exercise were lower in the cold trial compared to the warm trial $(p<0.0001)$, whilst cumulative urine output over the duration of the trials was greater in the cold ( $\mathrm{p}=0.036)$ Table 1).

More water was consumed throughout the duration of the warm trial compared to the cold trial $(\mathrm{p}=0.001)$ (Table 1). During the exercise period more water was consumed in the warm trial $(\mathrm{p}<0.05)$. Greater breakdown of the drinking periods showed that in the warm trial, more water was consumed during the first 30 minutes of the recovery period compared to 6090 minutes and 90-120 minutes $(\mathrm{p}<0.05)$ (Figure 2). Similar volumes of water were consumed during the exercise period and each 30 minute period during the recovery in the cold trial ( $>0.05$ ). During the exercise period subjects consumed water to replace $44 \pm 57 \%$ and $57 \pm 39 \%$ of water losses in the cold and warm trials respectively ( $\mathrm{p}=0.259$ ).

Reported feelings of thirst were similar between cold and warm trials at baseline, postexercise and after one and two hours of recovery ( $>0.05$ ) (Figure $4 a$ ). No difference between sample points was observed in the cold trial, however in the warm trial reported sensations of thirst were higher post-exercise compared to one $(p=0.012)$ and two hours of 
recovery $(\mathrm{p}=0.006)$. Reported sensations of mouth dryness were not different between trials and sample points (Figure $4 \mathrm{~b}$ ).

The amount of total sodium excreted was similar at post-exercise $(13 \pm 14 \mathrm{v} 8 \pm 2 \mathrm{mmol})$, and one (58 $\pm 45 \mathrm{v} 30 \pm 11 \mathrm{mmol})$ and two hours of the recovery (129 $\pm 86 \mathrm{v} 87 \pm 39 \mathrm{mmol})$ between cold and warm trials ( $p>0.05$ ) whilst the total amount of potassium excreted was similar post-exercise (16 $\pm 9 \mathrm{v} 11 \pm 4 \mathrm{mmol}$ ) but greater in the cold trial after one (70 $\pm 25 \mathrm{v}$ $44 \pm 14 \mathrm{mmol})$ and two hours of the recovery period (156 $\pm 44 \mathrm{v} 122 \pm 47 \mathrm{mmol})(\mathrm{p}<0.05)$.

\section{Blood analysis}

Haemoglobin concentrations increased in both trials following exercise $(\mathrm{p}<0.05)$ and remained elevated in the cold trial $(\mathrm{p}<0.05)$ (Figure $5 \mathrm{a})$. In the warm trial concentrations returned to baseline after one hour of recovery but were elevated above baseline values following two hours of recovery $(\mathrm{p}=0.018)$. Haematocrit values were similar between trials ( $>0.05$ ) but within trials were elevated at all sample points compared to baseline in the cold trial and post-exercise and after one hour of recovery in the warm trial $(\mathrm{p}<0.05)$ (Figure $5 b)$. Following one and two hours of recovery in the cold trial, although values did not return to baseline, they were lower than post-exercise samples $(\mathrm{p}<0.05)$. Plasma volume change from baseline was similar at post-exercise $(-11.3 \pm 2.0 \mathrm{v}-9.9 \pm 5.5 \%$ for the cold and warm trial respectively; $\mathrm{p}>0.05)$ and after one $(-5.9 \pm 3.2 \mathrm{v}-2.0 \pm 1.6 \%$ for the cold and warm trial respectively; $\mathrm{p}>0.05)$ and two hours of the recovery period $(-6.6 \pm 3.8 \mathrm{v}-5.5 \pm 2.7 \%$ for the cold and warm trial respectively; $\mathrm{p}>0.05)$. Blood volume decrease from baseline was greater in the cold trial compared to the warm trial after one hour of the recovery period $(-3.3 \pm 2.2 \mathrm{v}$ $-0.6 \pm 1.0 \%)(\mathrm{p}<0.05)$ but was similar at post-exercise $(-6.5 \pm 1.4 \mathrm{v}-6.3 \pm 3.3 \%)$ and after two hours $(-3.9 \pm 2.6 \mathrm{v}-3.1 \pm 1.7 \%)$ of the recovery period ( $\mathrm{p}>0.05)$. Red blood cell volume change from baseline was similar between trials at post-exercise $(-0.3 \pm 1.3 \mathrm{v}-1.3 \pm 1.1 \%)$ and after one ( $0.1 \pm 1.6$ v $1.2 \pm 1.2 \%)$ and two hours of the recovery $(-0.4 \pm 2.1$ v $0.0 \pm 0.5 \%)$ $(\mathrm{p}>0.05)$. In the cold trial, blood glucose concentrations did not change from baseline $(\mathrm{p}>0.05)$ (Figure 5c). In the warm trial, post-exercise concentrations were higher than baseline $(\mathrm{p}<0.0001)$ and compared to post-exercise concentrations in the cold trial $(\mathrm{p}=0.016)$. During recovery, blood glucose concentrations returned to baseline ( $\mathrm{p}>0.05)$.

In the cold trial serum osmolality was greater post-exercise compared to baseline $(p<0.0001)$ and there was a tendency to be greater compared to one $(\mathrm{p}=0.054)$ and two hours of recovery 
270

271

272

273 There was no difference in serum sodium concentrations between trials or over the duration

274 of the study $(\mathrm{p}<0.05)$. Serum sodium concentrations were $142 \pm 1 \mathrm{v} 142 \pm 1 \mathrm{mmol}^{-1}$ at

275 baseline, $142 \pm 1 \mathrm{v} 141 \pm 2$ mmol. $^{-1}$ post exercise, $142 \pm 1 \mathrm{v} 142 \pm 1 \mathrm{mmol}^{-1} \mathrm{l}^{-1}$ after one hour

276 of recovery and $142 \pm 1 \mathrm{v} 141 \pm 1 \mathrm{mmol}^{-1}$ after two hours of recovery in the cold and warm

277 trials respectively ( $\mathrm{p}>0.05)$. Serum potassium concentrations were higher post-exercise (5.0

$278 \pm 0.4$ and $5.0 \pm 0.3 \mathrm{mmol}^{-1} \mathrm{l}^{-1}$; cold and warm trial respectively) and after one hour of recovery

279 (5.1 \pm 0.4 and $4.9 \pm 0.2 \mathrm{mmol}^{-1}{ }^{-1}$; cold and warm trial respectively) compared to baseline (4.6

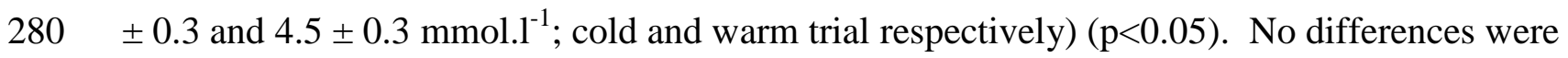
281

282

283

284

285

286

287

288

289

290

291

292

293

294 Core and skin temperature

295

296

297

298

299

300

301

302 observed between trials at each sample point.

\section{Correlations}

Total water intake was positively related to cumulative urine output in both the cold ( $\mathrm{r}=0.851$, $\mathrm{p}=0.002$ ) and the warm trials ( $\mathrm{r}=0.949, \mathrm{p}<0.0001$ ), however, water intake during each hour of the trial was not related to corresponding urine output volume in both trials (cold, $r=0.218$, $\mathrm{p}=0.246$; warm, $\mathrm{r}=0.130, \mathrm{p}=0.492$ ). No relationship was observed between serum osmolality, subjective feelings of thirst and mouth dryness and the subsequent water intake in the following monitored time period. Serum osmolality was positively related to feelings of thirst $(\mathrm{r}=0.429, \mathrm{p}=0.011)$ and mouth dryness $(\mathrm{r}=0.470, \mathrm{p}=0.005)$ in the cold trial but there was no relationship with feelings of thirst $(\mathrm{r}=0.267, \mathrm{p}=0.127)$ and mouth dryness $(\mathrm{r}=0.145$, $\mathrm{p}=0.412$ ) in the warm trial.

Core temperatures were similar between trials ( $>0.05$ ) (Figure 6a). In both trials, during exercise, core temperature rose $(\mathrm{p}<0.05)$ before returning to baseline values during the recovery period. Mean weighted skin temperature was similar throughout the warm trial ( $\mathrm{p}>0.05)$. During the cold trial, skin temperature decreased during the exercise period $(p<0.05)$ but returned to baseline values on exiting the environmental chamber $(p>0.05)$ (Figure 6b).

Rating of perceived exertion, heart rate and thermal sensation 
303 During exercise, RPE values were similar between trials, however after 30 minutes RPE 304 values were lower in the cold trial $(14 \pm 1)$ compared to the warm trial $(15 \pm 1)(\mathrm{p}<0.0001)$. 305 Heart rate values were lower after $20\left(65 \pm 11 \mathrm{v} 72 \pm 12\right.$ beats.min $\left.{ }^{-1} ; \mathrm{p}<0.0001\right)$ and 40 306 minutes $\left(61 \pm 10 \mathrm{v} 72 \pm 11\right.$ beats. $\mathrm{min}^{-1}$; $\left.\mathrm{p}=0.006\right)$ of the recovery period in the cold trial. No 307 difference was observed during other time points ( $\mathrm{p}>0.05)$. During exercise, mean heart rate 308 values were $144 \pm 11$ beats. $\min ^{-1}$ and $154 \pm 13$ beats. $\mathrm{min}^{-1}$ in the cold and warm trials 309 respectively. During exercise thermal sensation was lower in the cold after $10(-4 \pm 2$ v $3 \pm$

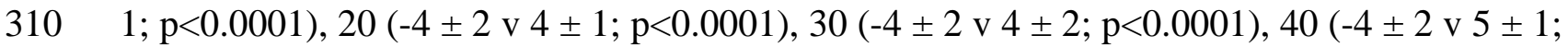

$311 \mathrm{p}<0.0001), 50(-4 \pm 2$ v $5 \pm 2 ; \mathrm{p}<0.0001)$ and 60 minutes $(-4 \pm 2$ v $5 \pm 1 ; \mathrm{p}<0.0001)$. 
315 The aim of this study was to assess voluntary water intake during and following moderate

316 exercise in either a warm or cold environment. In both trials, indication of hydration status

317 through body mass change showed similar body mass losses despite reduced voluntary water

318 intake in the cold.

Ad libitum water intake appeared to prevent body mass losses greater than $2 \%$ occurring during and following exercise in cold and warm conditions. It has been shown that during exercise, ad libitum water intake, when compared to prescribed volumes of water replacement, can prevent body mass losses of greater than 2\% (Dugas, Oosthuizen, Tucker, \& Noakes, 2009). Ad libitum water intake is believed to be largely driven by sensations of thirst, and this has thought to be sufficient to replace water losses (Greenleaf, 1992). However, ad libitum water intake can be affected by inappropriate sensations and/or inappropriate interpretations of thirst (Maughan \& Shirreffs, 2010). If ad libitum water intake results in too little water consumed then dehydration levels may be greater than a $2 \%$ body mass loss (Cheuvront \& Haymes, 2001). If too much is consumed, so that there is a gain in body mass, then there is often an accompanying increase in urine output and increased water losses (Wong, Williams, Simpson, \& Ogaki, 1998). In the current study all subjects prevented a $2 \%$ body mass loss from occurring, and with the exception of one subject in the cold trial and two in the warm trial, did not consume so much water for weight gain to occur during the exercise period (one subject in the cold and two in the warm trial gained weight following the exercise period and so consumed more water than they lost). By the completion of the trials all subjects were in negative water balance but not at a level that was likely to affect endurance performance ( $>2 \%$ body mass loss) (Sawka et al., 2007). When water intake was factored out, 4 subjects in the cold and 6 in the warm condition would have experienced body mass losses greater than $2 \%$, but due to voluntary water intake were able to prevent this.

Despite the difference in water intake between the cold and warm trials, body mass loss was similar in both trials. This suggests that water intake was adjusted to suit the physiological responses to the environment and therefore was appropriate for the situation. Subjects were able to consume enough water to offset a sufficient volume of the water losses through sweating, respiration and urine output. Larger sweat losses in the warm trial were offset with 
347 increased voluntary water intake. As environmental temperatures increase, heat loss by 348 evaporation increases, with cooling by convection, conduction and radiation becoming less 349 effective (Galloway \& Maughan, 1997). In the warm trial, in an attempt to dissipate heat and 350 prevent rises in core temperature, there was increased sweat losses and subsequent increased water intake to replace water losses. In addition to similar body mass losses, similar values for serum osmolality, urine and serum sodium and potassium concentrations and plasma volume changes between trials confirmed that water intake within each trial was sufficient to prevent large levels of dehydration.

355

Individual water intake patterns were varied within and between trials. In the cold trial two subjects consumed no water during the exercise period, whilst one subject consumed $0.959 \mathrm{l}$, equating to a $177 \%$ replacement of the water lost. Maughan et al. (2005) found large variation in individual water intake patterns during a 90 minute football training session in the cold $\left(5.1 \pm 0.7^{\circ} \mathrm{C}, 81 \pm 6 \% \mathrm{RH}\right)$ (mean intake $0.423 \pm 0.215 \mathrm{l}$, range $(0.044-0.951 \mathrm{l})$. In addition Maughan and Shirreffs (2008) have also recommended that athletes create individualised hydration strategies. In the present study, those that consumed smaller amounts relative to other subjects repeated the trend in the second trial. Translation to a practical setting would suggest that during exercise in the cold or in the warm it is important to cater to individual needs and identify those that may be consuming too much water. This could potentially have lead to unnecessary weight gain, which can often be conflicting for maximal sporting performance. Furthermore an increase in urine output can increase water losses (Wong et al., 1998) and may provide inconvenience through increased frequency of urination. It is also important to identify those that are not completely responding to thirst signals or have incorrect thirst signals and are not consuming sufficient water. However, identification of these individuals is difficult as it was not known whether subjects were drinking in response to sensations of thirst or perhaps due to a habitual response. Asking them this question may have influenced water consumption.

A greater cumulative urine output was observed in the cold trial and has been shown previously following cold exposure (O’Brien et al., 1998). However, O’Brien and colleagues found that this only occurred when the participant was in a euhydrated condition suggesting than in states of hypohydration urine output was reduced to prevent water loss. To increase reabsorption of water in the kidneys by increasing permeability to water of the collecting ducts and reduce urine output there is release of vasopressin to activate the V2R receptors in 
381 the kidney (Bankir, 2001). In the cold, vasoconstriction of the peripheral blood vessels and

382

383

384

385

386

387

388

389

390

391

392

393

394

395

396

397

398

399

400

401

402

403

404

405

406

407

408

409

410

411

412

413

414 redistribution of blood volume to the central areas of the body causes an increase in central blood pressure (Lennquist, Granberg, \& Wedin, 1974). The increase in pressure is detected as increased extracellular water and therefore is removed resulting in increased urine production (Stricker \& Verbalis, 1988). In the current study, the lack of difference in individual urine outputs between the trials at each timepoint may be attributed to the time spent in the different environmental conditions. Subjects did not rest in the cold environment and so once the exercise protocol had finished, the effect of the environment on causing coldinduced diuresis was diminished. Despite subjects not resting in the cold environment following the exercise period, it appeared that there was still a marginal effect of coldinduced diuresis. This was indicated by the greater cumulative urine output measured over the duration of the cold trial.

Serum osmolality values were greater post-exercise in both trials compared to baseline. In addition, the post-exercise serum osmolality values in the cold trial were greater than the threshold for thirst outlined by Phillips, Rolls, Ledingham, Forsling, and Morton (1985) (290 mOsmol. $\mathrm{kg}^{-1}$ ). However, water intake was lower and reported sensations of thirst were similar, compared to values in the warm trial. Above this threshold value, it has been reported that the first sensation of thirst occurs, ultimately resulting in a desire to drink. In the cold it has also been suggested that there is a blunted thirst response which may affect water intake volumes (Kenefick et al., 2008). Following $30 \mathrm{~min}$ exposure to the cold, Kenefick and colleagues reported that the sensation of thirst was attenuated to a serum osmolality threshold of approximately 304 mOsmol. $\mathrm{kg}^{-1}$. This attenuation of thirst, resulting from the cold-exposure, could be negated by an increase in plasma osmolality, in this instance, through sodium chloride ingestion. Yet, unlike in the current study the subsequent effect of thirst sensations on water intake behaviours was not examined. In the current study, the reduced water intake in the cold trial, despite similar rises in serum osmolality, would suggest that there was a blunting of the thirst response. Due to the relatively small duration of the exercise protocol, and thus cold exposure, there appeared not to be sufficient time for the blunted thirst response to have a greater impact on voluntary water intake.

Previous studies have examined the response to cold exposure without periods of exercise (Kenefick et al., 2008: O’Brien et al., 1998: O’Brien, Freund, Young, \& Sawka, 2005) and have not combined this with a recovery period allowing ad libitum water rehydration to be 
415 monitored. Although in this study, the recovery period was at a temperature of 416 approximately $22.2^{\circ} \mathrm{C}$; therefore not causing continual exposure to the cold environment, this 417 situation was felt to occur more readily in a sporting situation. Often, following completion 418 of exercise, individuals retreat to warmer environments and only remain exposed to the cold 419 when a warmer environment is not accessible. It is possible that longer exposure to the cold, 420 or exposure without the heat generating effect of exercise, would have also exacerbated the 421 blunted thirst response and increased urine output.

422

423 Conclusion

424 Voluntary water intake was less in the cold environment, however in both the warm and cold 425 environment, ad libitum water intake was sufficient to ensure an appropriate state of 426 hydration. In the cold there appeared to a blunted thirst response, however the severity and 427 length of the cold exposure was not enough to exacerbate this problem in relation to 428 hydration status. In a practical setting, it appears the body adjusts to the magnitude of 429 physiological and behavioural cues in different environments to ensure large water deficit do 430 not accrue. Despite a blunted thirst response in the cold, water intake was regulated to an 431 appropriate level that resulted in similar body mass losses in both environmental conditions.

432 Due to reduced sweat losses, those exercising in a cold environment will find that despite a 433 blunted thirst response, desire and necessity to drink will be sufficient to prevent large water 434 losses. 
436

437

438

439

440

441

442

443

444

445

446

447

448

449

450

451

452

453

454

455

456

457

458

459

460

461

462

References

Armstrong, L.E., Soto, J.A.H., Hacker, F.T., Casa, D.J., Kavouras, S.A., \& Maresh, C.M. (1998). Urinary indices during dehydration, exercise, and rehydration. International Journal of Sports Nutrition, 8, 345-355.

Bankir, L. (2001). Antidiuretic action of vasopressin: quantitative aspects and interaction between V1a and V2 receptor-mediated effects. Cardiovascular Research, 51, 372-390.

Cheuvront, S.N., Carter, R., Castellani, J.W., \& Sawka, M.N. (2005). Hypohydration impairs endurance exercise performance in temperate but not cold air. Journal of Applied Physiology, 99, 1972-1976.

Cheuvront, S.N., Carter, R., \& Sawka, M.N. (2003). Fluid balance and endurance exercise performance. Current Sports Medicine Reports, 2, 202-208.

Cheuvront, S.N., \& Haymes, E.M. (2001). Ad libitum fluid intakes and thermoregulatory responses of female distance runners in three environments. Journal of Sports Sciences, $19,845-854$.

Dill, D.B., \& Costill, D.L. (1974). Calculation of percentage changes in volumes of blood, plasma, and red-cells in dehydration. Journal of Applied Physiology, 37, 247-248.

Dugas, J.P., Oosthuizen, U., Tucker, R., \& Noakes, T.D. (2009). Rates of fluid ingestion alter pacing but not thermoregulatory responses during prolonged exercise in hot and humid conditions with appropriate convective cooling. European Journal of Applied Physiology, 105, 69-80.

Freund, B.J., Sawka, M.N. (1995). Influence of cold stress on human fluid balance. In Marriott BM (Ed.), Nutrient requirements for work in cold and high-altitudes (pp161180). Washington D.C.: National Academy of Sciences.

Galloway, S.D.R., \& Maughan, R.J. (1997). Effects of ambient temperature on the capacity to perform prolonged cycle exercise in man. Medicine and Science in Sports and Exercise, 29, 1240-1249.

Grandjean, A.C., \& Grandjean, N.R. (2007). Dehydration and cognitive performance. Journal of the American College of Nutrition, 26, 549S-554S. 
464 Greenleaf, J.E. (1992). Problem - Thirst, drinking behavior, and involuntary dehydration. Medicine and Science in Sports and Exercise, 24, 645-656.

466

467

468

469

470

471

472

473

474

475

476

477

478

479

480

481

482

483

484

485

486

487

488

489

490

Kenefick, R.W., Hazzard, M.P., Mahood, N.V., \& Castellani, J.W. (2004a). Thirst sensations and AVP responses at rest and during exercise-cold exposure. Medicine and Science in Sports and Exercise, 36, 1528-1534.

Kenefick, R.W., Hazzard, M.P., Mahood, N.V., \& Castellani, J.W. (2004b). Hypohydration effects on thermoregulation during moderate exercise in the cold. European Journal of Applied Physiology, 92, 565-570.

Kenefick, R.W., St Pierre, A., Riel, N.A., Cheuvront, S.N., \& Castellani, J.W. (2008). Effect of increased plasma osmolality on cold-induced thirst attenuation. European Journal of Applied Physiology, 104, 1013-1019.

Lennquist, S., Granberg, P.O., \& Wedin, B. (1974). Fluid balance and physical work capacity in humans exposed to cold. Archives of Environmental Health, 29, 241-249.

Maughan, R.J., \& Shirreffs, S.M. (2008). Development of individual hydration strategies for athletes. International Journal of Sports Nutrition and Exercise Metabolism, 18, 457472.

Maughan, R.J., \& Shirreffs, S.M. (2010). Development of hydration strategies to optimize performance for athletes in high-intensity sports and in sports with repeated intense efforts. Scandinavian Journal of Medicine \& Science in Sports, 20, 59-69.

Maughan, R.J., Shirreffs, S.M., Merson, S.J., \& Horswill, C.A. (2005). Fluid and electrolyte balance in elite male football (soccer) players training in a cool environment. Journal of Sports Sciences, 23, 73-79.

Murray, R. (1995). Fluid needs in hot and cold environments. International Journal of Sports Nutrition, 5, S62-S73.

O'Brien, C., Freund, B.J., Young, A.J., \& Sawka, M.N. (2005). Glycerol hyperhydration: physiological responses during cold-air exposure. Journal of Applied Physiology, 99,515-521. 
491

492

493

494

495

496

497

498

499

500

501

502

503

504

505

506

507

508

509

510

511

512

513

514

515

516

517

O'Brien, C., Young, A.J., \&Sawka, M.N. (1998). Hypohydration and thermoregulation in cold air. Journal of Applied Physiology, 84, 185-189.

Phillips, P.A., Rolls, B.J., Ledingham, J.G.G., Forsling, M.L., \& Morton, J.J. (1985). Osmotic thirst and vasopressin release in humans - a double-blind crossover study. American Journal of Physiology, 248, R645-R650.

Ramanathan, N.L. (1964). New weighting system for mean surface temperature of human body. Journal of Applied Physiology, 19, 531-533.

Sawka, M.N., Burke, L.M., Eichner, E.R., Maughan, R.J., Montain, S.J., \& Stachenfeld, N.S. (2007). Exercise and fluid replacement. Medicine and Science in Sports and Exercise, 39, 377-390.

Seifert, J.G., Burke, E.R., White, A., \& Luetkemeier, M.J. (2006). The effects of ad libitum fluid ingestion on fluid balance during alpine skiing in recreational skiers. Journal of Sports Sciences, 24, 137-142.

Shirreffs, S.M., Aragon-Vargas, L.F., Chamorro, M., Maughan, R.J., Serratosa, L., \& Zachwieja, J.J. (2005). The sweating response of elite professional soccer players to training in the heat. International Journal of Sports Medicine, 26, 90-95.

Shirreffs, S.M., \& Maughan, R.J. (1998). Urine osmolality and conductivity as indices of hydration status in athletes in the heat. Medicine and Science in Sports and Exercise, 30, 1598-1602.

Stricker, E.M., \& Verbalis, J.G. (1988). Hormones and behavior - the biology of thirst and sodium appetite. American Scientist, 76, 261-267.

Wendt, D., van Loon, L.J.C., \& Lichtenbelt, W.D.V.M. (2007). Thermoregulation during exercise in the heat - strategies for maintaining health and performance. Sports Medicine, 37, 669-682.

Wong, S.H., Williams, C., Simpson, M., \& Ogaki, T. (1998). Influence of fluid intake pattern on short-term recovery from prolonged, submaximal running and subsequent exercise capacity. Journal of Sports Sciences, 16, 143-152. 
519 List of figures

520 Figure 1 Schematic diagram indicating the testing protocol. Arrows represent sampling 521 points. SFQ denotes subjective feelings questionnaire

522 Figure 2 Voluntary water intake (l) during each trial. ${ }^{*}$ different to exercise period $(\mathrm{p}<0.05) .{ }^{\text {\# }}$

523 different to $0-30 \mathrm{~min}(\mathrm{p}<0.05){ }^{\dagger}$ different between trials $(\mathrm{p}<0.05)$. Mean $\pm \mathrm{SD}$

524 Figure 3 Serum osmolality over the duration of each trial (mOsmol. $\mathrm{kg}^{-1}$ ). ${ }^{*}$ different to 525 baseline $(\mathrm{p}<0.05)$. B denotes baseline sample, PE denotes post-exercise sample. Mean \pm SD

526 Figure 4 Subjective feelings of thirst (a) and mouth dryness (b) over the duration of each 527 trial. $0 \mathrm{~mm}=$ not at all thirsty / mouth not at all dry, $100 \mathrm{~mm}=$ very thirsty / mouth very dry. ${ }^{\text {\# }}$ 528 different to post-exercise in the warm trial $(\mathrm{p}<0.05)$. B denotes baseline sample, $\mathrm{PE}$ denotes 529 post-exercise sample. Mean \pm SD

530 Figure 5 Haemoglobin concentration (a), haematocrit (b) and blood glucose concentration (c) 531 over the duration of each trial. ${ }^{*}$ different to baseline $(\mathrm{p}<0.05) .{ }^{*}$ different to post-exercise $532(\mathrm{p}<0.05) .{ }^{\wedge}$ different to one hour of recovery $(\mathrm{p}<0.05) .{ }^{\dagger}$ different between trials $(\mathrm{p}<0.05) . \mathrm{B}$ 533 denotes baseline sample, PE denotes post-exercise sample. Mean \pm SD

534 Figure 6 Core $\left(\mathrm{T}_{\mathrm{c}}\right)$ temperature (a) and mean weighted skin $\left(\mathrm{T}_{\mathrm{sk}}\right)$ temperatures (b) over the 535 duration of each trial. ${ }^{*}$ Different to baseline, ${ }^{\dagger}$ different between trials $(\mathrm{p}<0.05)$. At 30 and $536150 \mathrm{~min}$ the decreases in core and skin temperature were caused when the Biopac connection 537 was interrupted to allow for body mass measurement. Mean \pm SD 


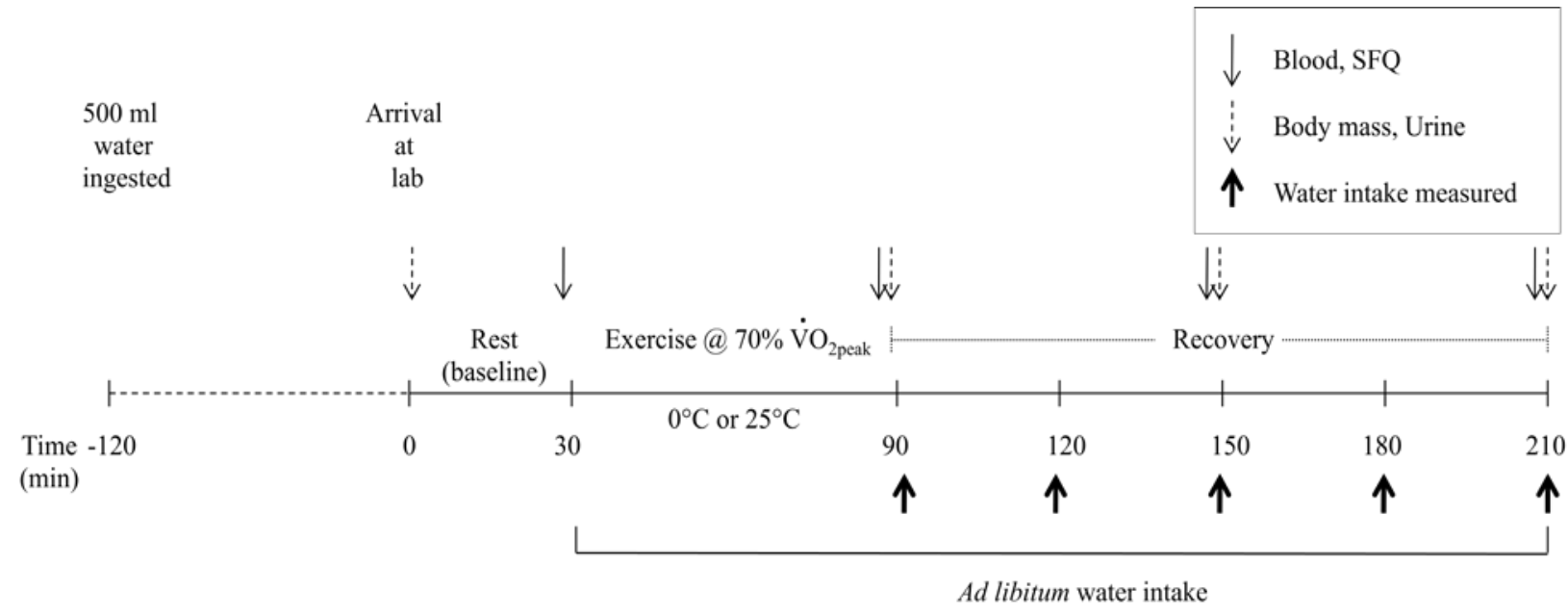

540 Figure 1

541 
542

543 Figure 2

544

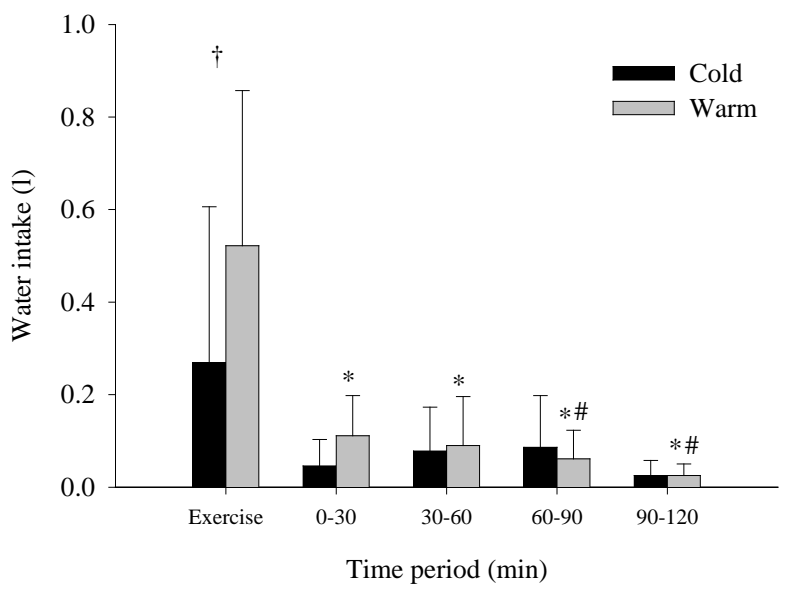

545 


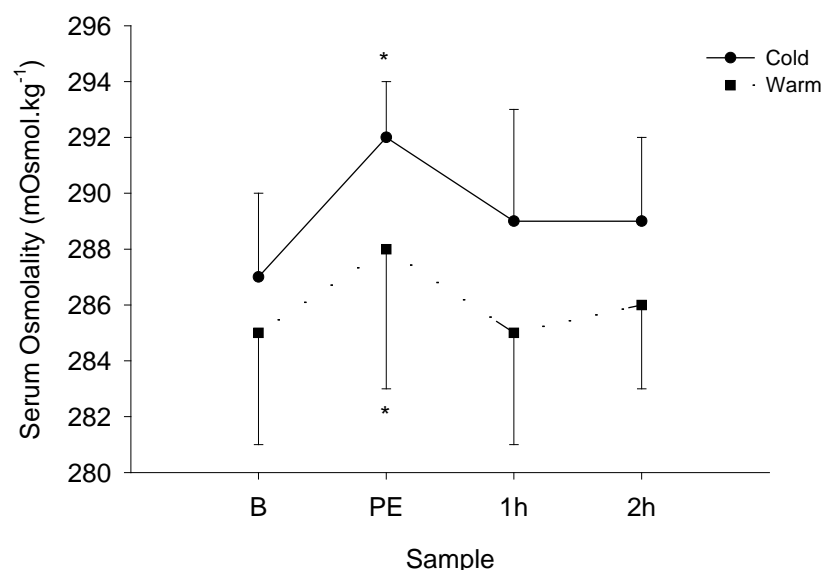

546

547

548 Figure 3

549 

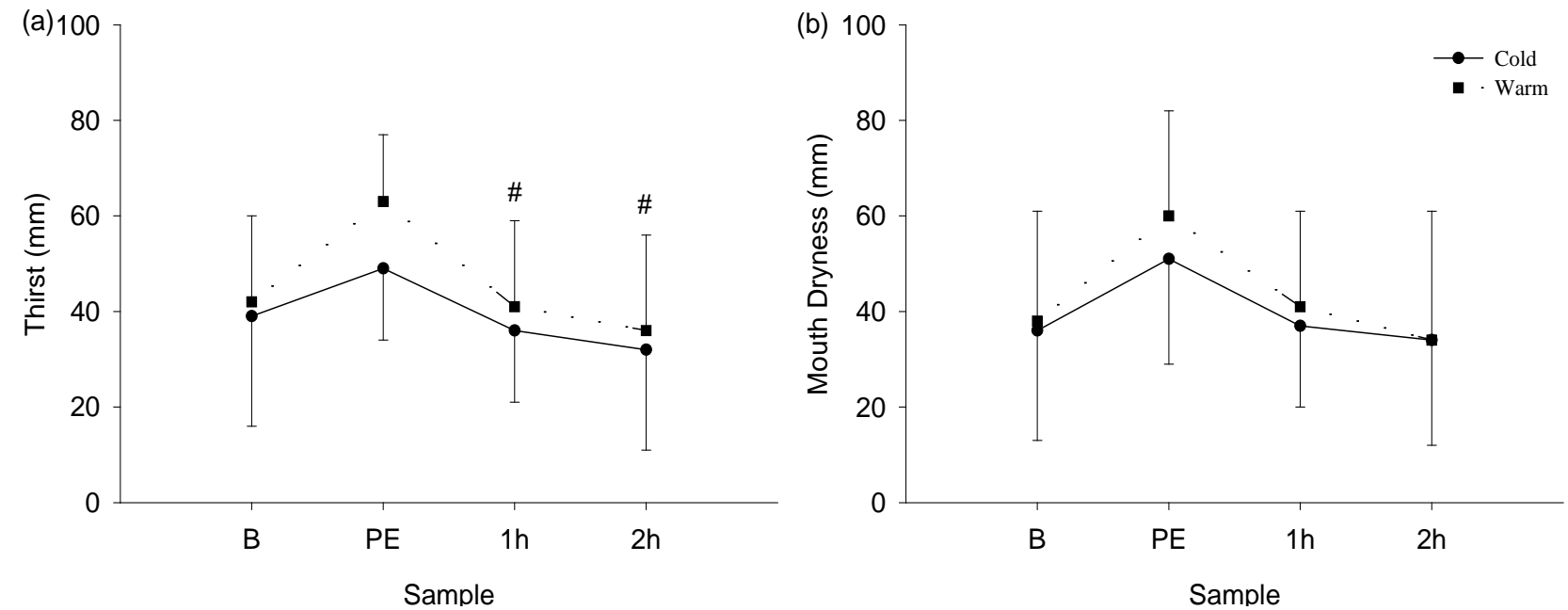

551 Figure 4

552 
553
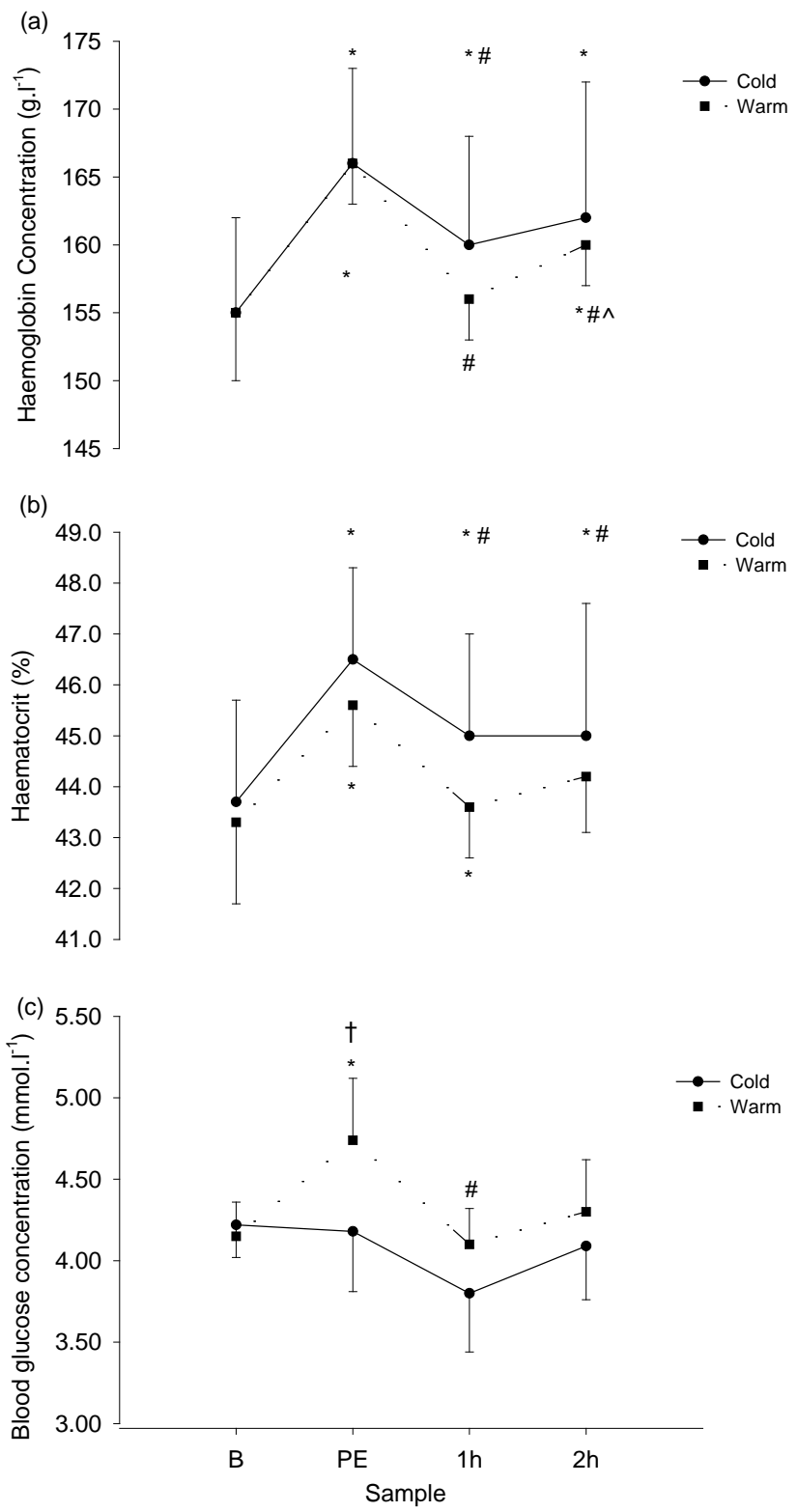

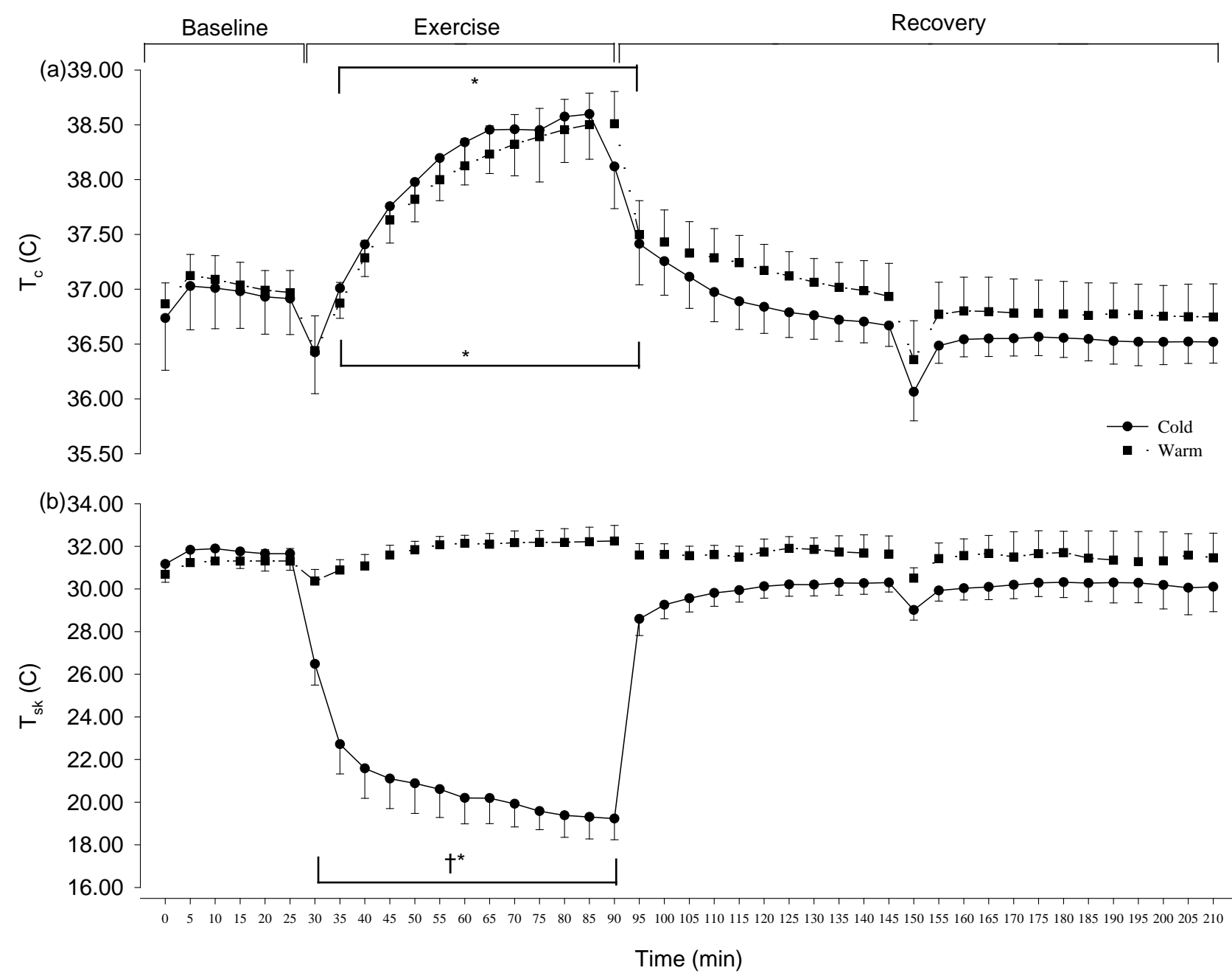
Table 1. Body mass changes and water balance between trials. ${ }^{*}$ denotes different between trials $(\mathrm{p}<0.05),{ }^{\wedge}$ denotes different between trials $(\mathrm{p}<0.0001),{ }^{\#}$ denotes different to baseline in the same trial $(\mathrm{p}<0.05)$. Mean $\pm \mathrm{SD}$

\begin{tabular}{|c|c|c|c|c|c|c|c|c|}
\hline & \multicolumn{8}{|c|}{ Timepoint } \\
\hline & \multicolumn{2}{|c|}{ Baseline to Post-Exercise } & \multicolumn{2}{|c|}{0 -1h recovery } & \multicolumn{2}{|c|}{ 1-2h recovery } & \multicolumn{2}{|c|}{ Total } \\
\hline & Warm & Cold & Warm & Cold & Warm & Cold & Warm & Cold \\
\hline Body mass change (\%) & $-0.63 \pm 0.56$ & $-0.50 \pm 0.50$ & $0.00 \pm 0.25$ & $-0.32 \pm 0.38$ & $-0.40 \pm 0.36$ & $-0.33 \pm 0.19$ & $-1.03 \pm 0.26^{\#}$ & $-1.15 \pm 0.34^{\#}$ \\
\hline Sweat loss (l) & $0.80 \pm 0.17^{*}$ & $0.39 \pm 0.13$ & $0.10 \pm 0.06$ & $0.05 \pm 0.03$ & $0.06 \pm 0.02$ & $0.05 \pm 0.02$ & $0.96 \pm 0.18^{\wedge}$ & $0.48 \pm 0.15$ \\
\hline Water intake (l) & $0.522 \pm 0.335^{*}$ & $0.269 \pm 0.337$ & $0.200 \pm 0.140^{*}$ & $0.124 \pm 0.147$ & $0.086 \pm 0.076$ & $0.111 \pm 0.134$ & $0.809 \pm 0.420^{\wedge}$ & $0.504 \pm 0.487$ \\
\hline Urine output (l) & $0.13 \pm 0.04$ & $0.22 \pm 0.19$ & $0.11 \pm 0.06$ & $0.30 \pm 0.24$ & $0.30 \pm 0.27$ & $0.29 \pm 0.20$ & $0.54 \pm 0.31$ & $0.81 \pm 0.46^{*}$ \\
\hline Respiratory loss (l) & Unknown & Unknown & Unknown & Unknown & Unknown & Unknown & Unknown & Unknown \\
\hline
\end{tabular}

